\title{
PENGARUH KEPEMIMPINAN, KOMITMEN ORGANISASI, KEPUASAN KERJA, DAN BALANCE SCORECARD TERHADAP KINERJA KARYAWAN PT XYZ DI JAKARTA
}

\author{
Rizki Oktaviani \\ Program Studi Magister Manajemen Universitas Tarumanagara \\ rizkioktaviani94.ro@gmail.com
}

\begin{abstract}
The purpose of this study are: First, to explore the effect of leadership on employees performance. Second, to explore the effect of organizational commitment on employees performance. Third, to explore the effect of job satisfaction on employees performance. Fourth, to explore the effect of balance scorecard on employees performance. Fifth, to explore the effect of leadership, organizational commitment, job satisfaction, and balance scorecard on employees performance. The population of this research are all employees of PT XYZ. This research uses a quantitative approach. The method of data collection is purposive sampling with 175 respondents. Data is collected using a questionnaire. The technique of data analysis used in this study was regression analysis to examine the hypotheses. The results are: (1) leadership has a significant effect on employees performance; (2) organizational commitment no significant effect on employees performance; (3) job satisfaction has a significant effect on employees performance; (4) balance scorecard has a significant effect on employees performance; (5) leadership, organizational commitment, job satisfaction and balance scorecard have a significant effect toward employees performance.
\end{abstract}

Keywords: Leadership, organizational commitment, job satisfaction, balance scorecard, employees performance.

\section{PENDAHULUAN}

Setiap perusahaan pasti membutuhkan karyawan untuk dapat menjalankan aktivitas dan mencapai visi dan misinya. Menghadapi perkembangan bisnis dan persaingan bisnis di Indonesia, tentunya perusahaan harus dapat memperhatikan mengenai karyawannya. Keberhasilan organisasi juga ditentukan oleh keberhasilannya dalam mengeloa sumber daya manusia. Masalah dalam manajemen sumber daya manusia yang patut untuk mendapatkan perhatian organisasi adalah masalah kinerja karyawan (Fu dan Deshpande, 2013). Kinerja karyawan dianggap penting bagi organisasi karena keberhasilan suatu organisasi dipengaruhi oleh kinerja itu sendiri. Khususnya kinerja karyawan. Kinerja karyawan adalah hasil kerja kualitatif dan kuantitatif yang dapat dicapai oleh karyawan dalam melaksanakan tugasnya sesuai dengan tanggung jawab yang diberikan kepadanya.

Dilihat dari revenue yang didapat dan tingkat turn over di PT. XYZ. Diperlukan pengkajian yang lebih mendalam mengenai kinerja karyawan dalam PT. XYZ. Karena kinerja karyawan yang baik akan dapat membantu mencapai tujuan sebuah perusahaan. Dan dengan adanya pengkajian yang lebih mendalam mengenai kinerja karyawan diharapkan manajemen dapat mengambil langkah dalam pencapaian tujuan perusahaan yang disebabkan oleh kinerja karyawan.

Oleh karena itu upaya- upaya untuk meningkatkan kinerja karyawan merupakan tantangan manajemen yang paling serius karena keberhasilan untuk mencapai tujuan dan kelangsungan hidup perusahaan tergantung pada kualitas kinerja sumber daya manusia yang ada di dalamnya. Salah satu faktor yang dapat digunakan untuk meningkatkan kinerja 
karyawan adalah kepemimpinan, komitmen organisasi, kepuasan kerja, dan peran dari adanya balance scorecard.

Tujuan dari penelitian ini adalah untuk mengetahui: (1) pengaruh kepemimpinan terhadap kinerja karyawan; (2) pengaruh komitmen organisasi terhadap kinerja karyawan; (3) pengaruh kepuasan kerja terhadap kinerja karyawan; (4) pengaruh balance scorecard terhadap kinerja karyawan; (5) pengaruh kepemimpinan, komitmen organisasi, kepuasan kerja, dan balance scorecard terhadap kinerja karyawan. Hasil penelitian ini diharapkan dapat memberikan informasi dan sebagai bahan pertimbangan dalam pengambilan keputusan yang berhubungan dengan kepemimpinan, komitmen organisasi, kepuasan kerja, balance scorecard dan kinerja karyawan di perusahaan.

\section{KAJIAN TEORI}

Kepemimpinan. Perilaku kepemimpinan telah dikembangkan dan diterapkan. Dan terus diteliti apa yang berkontribusi terhadap keberhasilan dan kegagalan kepemimpinan. Termasuk diantaranya, otokratis versus demokratis, berorientasi pada tugas versus berorientasi pada orang, dan pendekatan kontingensi. Saat ini, pendekatan kontingensi yang paling berpengaruh terhadap kepemimpinan adalah Path-Goal teori, yang dikembangkan oleh Robert House (Robbins, 2005). Teori ini menyatakan bahwa tujuan utama pemimpin adalah untuk membantu bawahan mencapai tujuan bawahan secara efektif, dan untuk memberi mereka arahan dan dukungan yang diperlukan untuk mencapai tujuan mereka sendiri serta orang-orang dari organisasi (Silverthorne, 2001). Daft (sebagaimana dikutip dari Lee dan Zaman, 2008:54) kepemimpinan sebagai hubungan pengaruh di antara para pemimpin dan pengikut yang menginginkan perubahan dan hasil yang mencerminkan tujuan bersama.

Path-Goal teori membagi kepemimpinan dalam empat klasifikasi, yaitu directive leadership (memulai struktur, berorientasi pada tugas) memberi tahu bawahan dengan tepat apa yang seharusnya mereka lakukan. Supportive leadership (consideration, berorientasi pada orang) menunjukkan kepedulian terhadap kesejahteraan bawahan dan kebutuhan pribadi. Participative leadership, berkonsultasi dengan bawahan tentang keputusan. Achievementoriented Leadership menentukan tujuan yang jelas dan menantang bagi bawahan.

Komitmen organisasi. Komitmen Organisasi mengacu pada keyakinan karyawan dalam tujuan dan nilai organisasi, keinginan untuk tetap menjadi anggota organisasi dan kesetiaan kepada organisasi (Mowday et al., 1982; Hackett et al., 2001). Dengan meningkatkan kecepatan dan mengikuti perubahan dalam organisasi, manajer terus-menerus mencari cara untuk menghasilkan komitmen karyawan, sehingga mereka harus mengetahui bagaimana menjadi kompetitif keuntungan dan peningkatan sikap kerja seperti kepuasan kerja, kinerja karyawan, ketidakhadiran, dan keinginan berpindah. Allen dan Meyer (1990) mengidentifikasi tiga komponen dalam komitmen organisasi :

(1) afektif;

(2) kelanjutan; dan

(3) komitmen normatif.

Kepuasan Kerja. Teori dari Spector (1994:2) mengatakan bawah kepuasan kerja sebagai sejauh mana orang suka (kepuasan) atau tidak suka (ketidakpuasan) pekerjaan mereka. Sesorang akan merasa puas dalam pekerjaan mereka ketika mereka menyukai pekerjaan yang mereka lakukan tersebut (Maleki, 2011:652 ). Kepuasan Kerja merupakan hubungan antara individu dan lingkungan kerja mereka seperti perasaan yang dimiliki individu terhadap pekerjaannya, sejauh mana individu menyukai dan menikmati saat melakukan pekerjaan mereka, dan presepsi karyawan tentang seberapa baik pekerjaan mereka memberikan hal-hal yang dipandang penting. 
Ada lima aspek dalam kepuasan kerja, yaitu pekerjaan itu sendiri, supervisi atasan, teman sekerja, promosi, gaji. Aspek lainya adalah kerja yang menantang, gajaran yang pantas atas pekerjaan, kondisi kerja yang mendukung, rekan kerja yang mendukung, kesesuaian pekerjaan dengan kepribadian (FauzanBaihaqi, 2010).

Balance Scorecard. Kaplan dan Norton (2000) mendefinisikan balanced scorecard adalah suatu kerangka kerja untuk mengintegrasikan berbagai ukuran dari perspektif keuangan, pelanggan, proses bisnis internal, pembelajaran dan pertumbuhan. Teymouri et al 2006 dalam Najjari (2015) mengatakan bahwa di antara berbagai metode yang telah dirancang untuk mengukur organisasi, Balance Scorecard adalah satu-satunya metode yang dapat menggambarkan bagaimana subdivisi dapat mempengaruhi kinerja seluruh organisasi. Kaplan dan Norton (1992) dalam penelitiannya mengatakan bahwa pendekatan baru ditemukan yaitu balance scorecard yang digunakan untuk mengevaluasi kinerja.

Ciptani (sebagaimana dikutip dari Yasssin et al 2016) mengemukakan, balanced scorecard dikembangkan untuk melengkapi pengukuran kinerja finansial karena kinerja perusahaan jika hanya diukur melalui perspektif keuangan, sebagai dampaknya kebanyakan perusahaan hanya mengejar kinerja keuangannya saja dengan mengabaikan potensi kinerja non-keuangan, seperti kepuasan konsumen, brand image, posisi pasar, kepemimpinan biaya (cost leadership), pemberdayaan dan komitmen karyawan, dan kinerja karyawan. Dapat disimpulkan bawah balance scorecard adalah adalah suatu tools yang digunakan untuk mengukur kinerja yang dapat memengaruhi kinerja. Terdapat empat perspektif dalam balanced scorecard yaitu finansial, pelanggan, proses bisnis internal, pembelajaran dan pertumbuhan. Pada penelitian ini yang akan dijadikan fokus penelitian dalam balanced scorecard adalah perspektif proses bisnis internal dan perspektif pembelajaran dan pertumbuhan.

Kinerja Karyawan. Mangkunagara (sebagaimana dikutip dari Sawitri 2016:27) mendefinisikan kinerja karyawan sebagai hasil kerja kualitatif dan kuantitatif yang dapat dicapai oleh karyawan dalam menjalankan tugasnya sesuai dengan tanggung jawab yang diberikan kepadanya. Motowidlo dan Van Scotter (1994) mengusulkan dua dimensi kinerja karyawan. Kinerja tugas (atau kinerja pekerjaan teknis) dan Kinerja kontekstual (atau kinerja pekerjaan interpersonal). Kinerja Karyawan merupakan variabel yang banyak digunakan dalam judul tesis dan umumnya digunakan sebagai variabel dependen.

\section{HIPOTESIS}

Pengaruh Kepemimpinan terhadap Kinerja Karyawan. Pada penelitian yang dilakukan oleh Babola (2016:942) ditemukan bahwa kepemimpinan signifikan mempengaruhi kinerja karyawan. Hasil serupa juga ditemukan oleh Basri et al (2016:51) dimana kepemimpinan memiliki pengaruh terhadap kinerja karyawan dalam suatu organisasi. Hal ini juga didukung oleh penelitian yang dilakukan oleh FauzanBaihaqi (2010:96) juga menemukan bahwa kepemimpinan memiliki pengaruh positif dan signifikan terhadap kinerja karyawan. Berdasarkan paparan di atas, maka hipotesis penelitian ini adalah sebagai berikut:

H1: Terdapat pengaruh kepemimpinan terhadap kinerja karyawan.

Pengaruh Komitmen Organisasi terhadap Kinerja Karyawan. Fu dan Deshpande (2013) dalam penelitiannya menyimpulkan bahwa komitmen organisasi memiliki pengaruh terhadap kinerja karyawan. Hal tersebut diperkuat oleh penelitian yang dilakukan oleh Lee dan Zaman (2008) yang menyimpulkan bahwa terdapat pengaruh komitmen organisasi terhadap kinerja karyawan walaupun tidak signifikan. Penelitian oleh Sawitri et al. (2016) juga menemukan bahwa komitmen organisasi memiliki pengaruh terhadap kinerja karyawan. Diperkuat oleh 
FauzanBaihaqi (2010) mengatakan bahwa komitmen organisasi mempengaruhi kinerja karyawan. Berdasarkan paparan di atas, maka hipotesis penelitian ini adalah sebagai berikut: H2: Terdapat pengaruh komitmen organisasi terhadap kinerja karyawan.

Pengaruh Kepuasan Kerja terhadap Kinerja Karyawan. Springer (2011) dalam penelitiannya menyimpulkan bahwa kepuasan kerja positif mempengaruhi kinerja karyawan. Penelitian lainnya yang dilakukan oleh Bowling et al. (2015) juga menemukan bahwa kepuasan kerja berpengaruh terhadap kinerja karyawan. Hur et al. (2015) dalam penelitiannya juga mengatakan bahwa kepuasan kerja mempengaruhi kinerja karyawan. Hal ini kemudian diperkuat oleh penelitian Babola (2016) yang menunjukkan bahwa kinerja karyawan dipengaruhi oleh kepuasan kerja, ketika karyawan puas terhadap pekerjaannya maupun lingkungan kerjanya maka akan mempengaruhi kinerja karyawan tersebut. Berdasarkan paparan di atas, maka hipotesis penelitian ini adalah sebagai berikut:

H3: Terdapat pengaruh kepuasan kerja terhadap kinerja karyawan.

Pengaruh Balance Scorecard terhadap Kinerja Karyawan. Penelitian yang dilakukan oleh Najjari et al (2015) menemukan bahwa bahwa balance scorecard memiliki pengaruh terhadap kinerja dan kepemimpinan karyawan. Hal ini kemudian diperkuat oleh penelitian yang dilakukan oleh Yassin et al (2016) dimana variabel balanced scorecard berpengaruh signifikan terhadap kinerja karyawan. Dan oleh Mumbi (2015) dimana hasil penelitiannya menunjukkan pengaruh balance scorecard terhadap kinerja karyawan. Berdasarkan paparan di atas, maka hipotesis penelitian ini adalah sebagai berikut:

H4: Terdapat pengaruh balance scorecard terhadap kinerja karyawan.

Pengaruh Kepemimpinan, Komitmen Organisasi, Kepuasan Kerja, dan Balance Scorecard terhadap Kinerja Karyawan. Sejalan dengan penelitian yang dilakukan oleh Babalola (2016); Basri et al (2016); FauzanBaihaqi (2010); Fu dan Deshpande (2013); Lee dan Zaman (2008); Sawitri et al. (2016); Hur et al. (2015); Springer (2011); Bowling et al. (2015); Najjari et al (2015); Yassin et al (2016); Mumbi (2015) dimana penelitian yang dilakukan oleh para peneliti terdahulu ini menemukan bahwa kepemimpinan, komitmen organisasi, kepuasan kerja, dan balance scorecard memiliki pengaruh terhadap kinerja karyawan.

Berdasarkan paparan di atas, maka hipotesis penelitian ini adalah sebagai berikut:

H5: Terdapat kepemimpinan, komitmen organisasi, kepuasan kerja, dan balance scorecard terhadap kinerja karyawan.

Berdasarkan uraian diatas, maka kerangka teoritis dalam penelitian ini adalah:

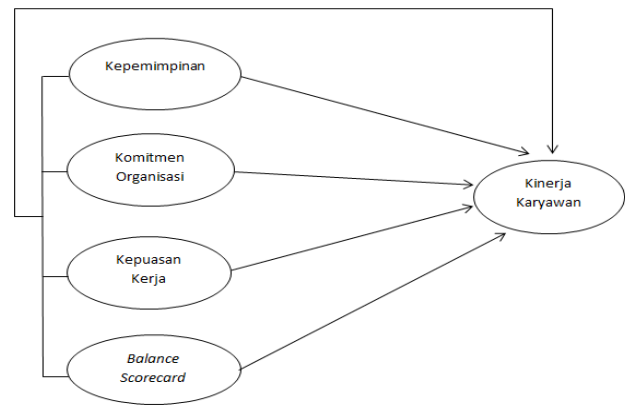

Gambar 1. Kerangka Teoritis

\section{METODE PENELITIAN}

Metode analisis yang digunakan yakni :

Analisis Deskriptif. Analisis deskriptif merupakan analisis yang memaparkan secara kualitatif perkembangan data data yang ada, baik data dalam bentuk tabel maupun grafik. Untuk memperkuat analisis empirik yang disesuaikan dengan hasil jawaban dari para responden. 
Regresi Linear Berganda. Regresi linear berganda digunakan untuk megetahui seberapa besar pengaruh variabel independen dari penelitian ini yaitu: Kepemimpinan, Komitmen Organisasi, Kepuasan Kerja, dan Balance Scorecard terhadap variabel dependen yaitu Kinerja Karyawan (Sekaran dan Bougie, 2013).

Persamaan umum regresi linear berganda adalah sebagai berikut:

$\mathrm{Y}^{\prime}=\mathrm{a}+\mathrm{b}_{1} \mathrm{X}_{1}+\mathrm{b}_{2} \mathrm{X}_{2}+\mathrm{b}_{3} \mathrm{X}_{3}+\mathrm{b}_{4} \mathrm{X}_{4}+\mathrm{e}$

Dimana: $\mathrm{Y}=$ Kinerja Karyawan $\mathrm{X} 1=$ variabel Kepemimpinan $\mathrm{X} 2=$ variabel Komitmen Organisasi $\mathrm{X} 3$ = variabel Kepuasan Kerja X1 = variabel Kepemimpinan $\mathrm{X} 2=$ variabel Komitmen Organisasi X4 = variabel Balance Scorecard $a=$ konstanta b1 $a=$ konstanta b1,b2,b3 = koefisien garis regresi e = error

Populasi dan Metode Pengambilan Sampel. Populasi dalam penelitian ini adalah para karyawan dan karyawati PT XYZ di Jakarta. Karena banyaknya jumlah karyawan dan karyawati PT XYZ dan keterbatasan penulis, maka tidak mungkin bagi penulis untuk melakukan penelitian berdasarkan populasi. Sampel dalam penelitian ini adalah karyawan dan karyawati PT XYZ di Jakarta, yang sudah bekerja minimal kurang dari 1 tahun agar dapat mencapai tujuan penelitian dan dapat membantu peneliti memperoleh informasi dari responden yang sesuai dengan kriteria yang ditetapkan peneliti dan dapat memberikan informasi yang diinginkan oleh peneliti. Metode pengambilan sampel yang digunakan dalam penelitian ini adalah non probability sampling, yang artinya tidak semua karyawan terpilih untuk menjadi sampel. Teknik pengambilan sampel yang digunakan dalam penelitian ini adalah purposive sampling. Ukuran sampel yang digunakan dalam penelitian ini adalah sebanyak 175 orang.

Variabel dan Pengukuran. Pada penelitian ini variable kepemimpinan, komitmen organisasi, kepuasan kerja, dan balance scorecard merupakan variable bebas, sedangkan kinerja karyawan merupakan variable terikat. Untuk mengukur variable ini, beberapa instrument diadaptasi dari studi literature penelitian sebelumnya. Skala pengukuran yang digunakan (kecuali profil responden) adalah skala likert lima poin dengan 1 menunjukkan "sangat tidak setuju" dan 5 menunjukan "sangat setuju".

Metode Analisis Data. Metode analisis data yang digunakan untuk menjawab masalah penelitian ini adalah menggunakan analisis regresi. Uji asumsi seperti uji normalitas, uji multikolinieritas dan uji heteroskedastisitas telah dilakukan sebelum analisis regresi dilakukan dan hasilnya menunjukan semua uji asumsi sudah terpenuhi. Taraf signifikansi yang digunakan dalam penelitian ini adalah 5\%. Pengujian dalam penelitian ini menggunakan program SPSS (Statistical Package for Social Science).

Pada penelitian ini, pengujian untuk analisis data dilakukan dengan membagi menjadi empat model yaitu model 1 digunakan untuk menguji hipotesis pertama yaitu menguji pengaruh kepemimpinan terhadap kinerja karyawan, model 2 digunakan untuk menguji hipotesis kedua yaitu menguji pengaruh komitmen organisasi terhadap kinerja karyawan, model 3 digunakan untuk menguji hipotesis ketiga yaitu menguji pengaruh kepuasan kerja terhadap kinerja karyawan, model 4 digunakan untuk menguji hipotesis keempat yaitu untuk menguji pengaruh balance scorecard terhadap kinerja karyawan. Dan model 5 digunakan untuk menguji hipotesis kelima yaitu untuk menguji pengaruh kepemimpinan, komitmen organisasi, kepuasan kerja, dan balance scorecard terhadap kinerja karyawan.

\section{HASIL DAN PEMBAHASAN}




\section{Analisis Deskriptif}

Profil Responden. Berdasarkan data yang telah dikumpukan pada penelitian ini diketahui bahwa karakteristik responden mayoritas adalah perempuan $(63,4 \%)$ dan laki-laki $(36,6 \%)$. Pendidikan responden mayoritas S1 (80,57\%). Usia mayoritas 18-29 tahun (73,1\%). Posisi responden mayoritas staff $(90,29 \%)$ dan supervisor $(9,71 \%)$.

Hasil Uji Validitas dan Reliabilitas. Hasil uji validitas menunjukan bahwa nilai corrected item total correlation semua butir pernyataan pada setiap variabel penelitian lebih besar dari 0,2, dengan demikian dapat ditarik kesimpulan bahwa semua pernyataan pada kepemimpinan, komitmen organisasi, kepuasan kerja, balance scorecard dan kinerja karyawan adalah valid. Sementara hasil dari pengujian reliabilitas seluruh variabel pada penelitian ini diperoleh nilai Cronbach Alpha setiap variabel > 0,7, maka dapat disimpulkan bahwa seluruh variabel yang digunakan dalam penelitian ini reliabel. Sehingga untuk selanjutnya item-item pada masing-masing variabel tersebut layak digunakan sebagai alat ukur.

\section{Uji Asumsi Klasik}

Uji Normalitas

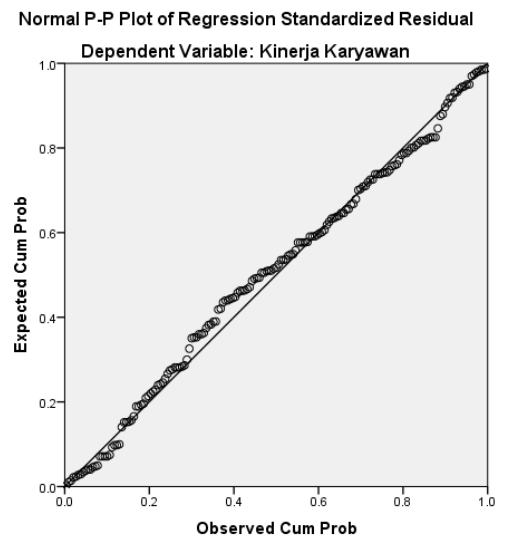

Gambar 2. Hasil Pengujian Normalitas

Berdasarkan hasil diatas, diketahui bahwa residual data menyebar di sekitar garis diagonal dan mengikuti arah garis diagonal,maka model regresi tersebut memenuhi asumsi normalitas.

Uji Multikolinearitas

a. Dependent Variable: Kinerja Karyawan

\begin{tabular}{|c|c|c|c|c|c|c|c|}
\hline \multirow[b]{2}{*}{ Model } & \multicolumn{2}{|c|}{$\begin{array}{c}\text { Unstandardized } \\
\text { Coefficients }\end{array}$} & \multirow{2}{*}{$\begin{array}{c}\begin{array}{c}\text { Standardiz } \\
\text { ed } \\
\text { Coefficient } \\
\text { s }\end{array} \\
\text { Beta } \\
\end{array}$} & \multirow[b]{2}{*}{$\mathrm{t}$} & \multirow[b]{2}{*}{ Sig. } & \multicolumn{2}{|c|}{$\begin{array}{c}\text { Collinearity } \\
\text { Statistics }\end{array}$} \\
\hline & B & Std. Error & & & & $\begin{array}{c}\text { Toleran } \\
\text { ce }\end{array}$ & VIF \\
\hline 1 (Constant) & $\begin{array}{r}1.19 \\
2\end{array}$ & .240 & & 4.972 & .000 & & \\
\hline $\begin{array}{l}\text { Kepemimpi } \\
\text { nan }\end{array}$ & .154 & .052 & .199 & 2.936 & .004 & .595 & 1.680 \\
\hline $\begin{array}{l}\text { Komitmen } \\
\text { Organisasi }\end{array}$ & .037 & .057 & .037 & .643 & .521 & .828 & 1.208 \\
\hline $\begin{array}{l}\text { Kepuasan } \\
\text { Kerja }\end{array}$ & .157 & .055 & .188 & 2.824 & .005 & .620 & 1.612 \\
\hline $\begin{array}{l}\text { Balance } \\
\text { Scorecard }\end{array}$ & .355 & .058 & .462 & 6.165 & .000 & .489 & 2.047 \\
\hline
\end{tabular}


Tabel 1. Hasil Pengujian Multikolinieritas

Berdasarkan hasil tabel 1 diatas, diketahui bahwa nilai VIF masing-masing variabel lebih kecil dari 10. Sehingga dapat disimpulkan bahwa data yang kita uji tidak terjadi multikolinearitas.

\section{Uji Heteroskedastisitas}

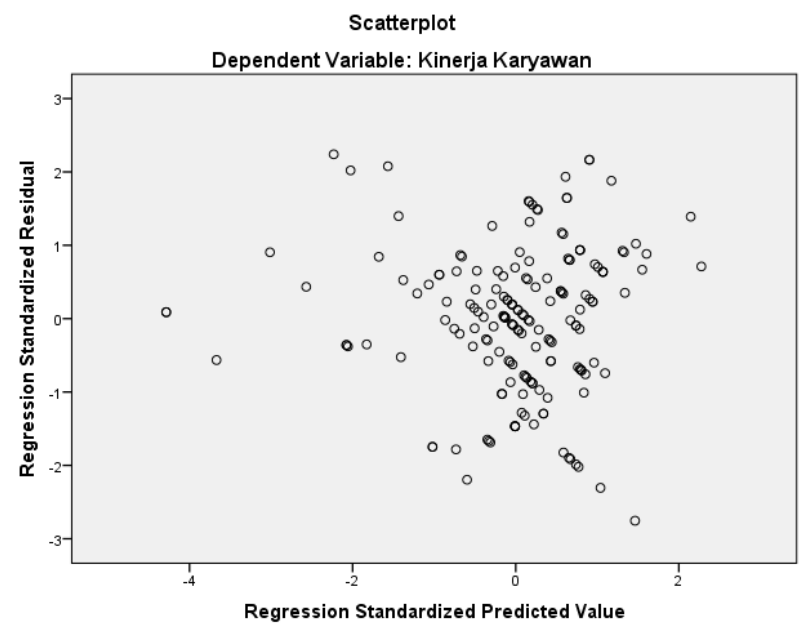

Gambar 3. Hasil Pengujian Heteroskedastisitas

Dari gambari diatas dapat dilihat bahwa titik-titik menyebar diatas dan dibawah angka nol dari sumbu Y, maka dapat disimpulakan tidak terjadi heteroskedastisitas.

\section{Analisis Regresi Liner Berganda}

\begin{tabular}{|l|l|r|r|}
\hline & Model & B & \multicolumn{1}{|c|}{ Sig } \\
\hline 1 & Constant $)$ & 1,192 & $0,000 * * *$ \\
\hline & Kepemimpinan & 0,154 & $0,004 * * *$ \\
\hline Komitmen Organisasi & 0,037 & 0,521 \\
\hline & Kepuasan Kerja & 0,157 & $0,005 * * *$ \\
\hline Balance Scorecard & 0,355 & $0,000 * * *$ \\
\hline $\mathrm{F} \mathrm{48,783}$ & & $0,000 * * *$ \\
\hline $\mathrm{R}^{2} 0,534$ & & \\
*** Signifikan $\alpha 0,01$ & & \\
$* *$ Signifikan pada $\alpha 0,005$ & & \\
& $*$ Signifikan pada $\alpha 0,01$
\end{tabular}

Tabel 2. Hasil Analisis Regresi Berganda

Diperoleh nilai koefisien regresi pada variabel Kepemimpinan adalah sebesar 0,154. Ini berarti bahwa dengan faktor lain dianggap konstan, maka setiap peningkatan Kepemimpinan maka kinerja akan ikut meningkat sebesar 0,154. Nilai koefisien regresi pada variabel Komitmen Organisasi adalah sebesar 0.037. Ini berarti bahwa dengan faktor lain dianggap konstan, maka setiap peningkatan Komitmen Organisasi maka kinerja akan ikut meningkat sebesar 0.037. Nilai koefisien regresi pada variabel Kepuasan Kerja adalah sebesar 0.157. Ini berarti bahwa dengan faktor lain dianggap konstan, maka setiap peningkatan Kepuasan Kerja maka kinerja akan ikut meningkat sebesar 0.157. Nilai koefisien regresi pada variabel Balance Scorecard adalah sebesar 0.355. Ini berarti bahwa dengan faktor lain dianggap konstan, maka setiap peningkatan Balance Scorecard maka kinerja akan ikut meningkat 
sebesar 0.355. Maka berdasarkan data di atas dapat dihasilkan persamaan regresi sebagai berikut: JP $=1,192+0,154 \mathrm{~L}+0,037 \mathrm{OC}+0,157 \mathrm{JS}+0,355 \mathrm{BS}$.

\section{Hasil Pengujian Hipotesis}

Hipotesis pertama adalah menguji pengaruh signifikan kepemimpinan terhadap kinerja karyawan. Hasil hipotesis pertama ini menunjukkan bahwa terdapat pengaruh positif dan signifikan kepemimpinan $(0,004<0,05)$ terhadap kinerja karyawan. Hal ini kepemimpinan berpengaruh positif dan signifikan mempengaruhi kinerja karyawan. Ketika kepemimpinan seorang atasan baik dan adil maka akan dapat berpengaruh terhadap kinerja karyawan. Hipotesis kedua adalah menguji pengaruh signifikan komitmen organisasi terhadap kinerja karyawan. Hasil hipotesis kedua ini menunjukkan bahwa terdapat pengaruh signifikan komitmen organisasi $(0,521>0,05)$ terhadap kinerja karyawan. Hal ini tidak sesuai dengan penelitian sebelumnya oleh Fu dan Deshpande (2013) dalam penelitiannya menyimpulkan bahwa komitmen organisasi memiliki pengaruh positif dan signifikan terhadap kinerja karyawan. Tetapi hasil penelitian ini sesuai dengan penelitian sebelumnya oleh Lee dan Zaman (2008) yang menyimpulkan bahwa terdapat pengaruh komitmen organisasi terhadap kinerja karyawan walaupun tidak signifikan. Di sisi lain, temuan penelitian ini juga sesuai dengan Lee dan Mowday (1989), hal ini bisa tidak signifikan di mana ada hubungan yang dapat diabaikan antara komitmen dan kinerja karyawan. Perbedaan dapat karena demografi sampel penelitian - pekerja muda berpendidikan tinggi yang mungkin puas dengan pekerjaan mereka dan performancenya bagus tetapi tidak berkomitmen pada organisasi mereka. Kinerja mereka dapat dipengaruhi oleh faktor lain selain dari komitmen saja. Hipotesis ketiga menguji pengaruh signifikan kepuasan kerja terhadap kinerja karyawan. Hasil hipotesis ketiga ini menunjukkan bahwa terdapat pengaruh signifikan kepuasan kerja $(0,005<0,05)$ terhadap kinerja karyawan. Hal ini sesuai dengan penelitian sebelumnya oleh Springer (2011) dalam penelitiannya menyimpulkan bahwa kepuasan kerja positif dan signifikan mempengaruhi kinerja karyawan. Hipotesis keempat menguji pengaruh signifikan balance scorecard terhadap kinerja karyawan. Hasil hipotesis keempat ini menujukkan bahwa terdapat pengaruh signifikan balance scorecard $(0,000<0,05)$ terhadap kinerja karyawan. Hal ini sesuai dengan penelitian sebelumnya oleh Yassin et al (2016) dimana variabel balanced scorecard berpengaruh signifikan terhadap kinerja karyawan. Hipotesis kelima secara keseluruhan menguji pengaruh signifikan kepemimpinan, komitmen organisasi, kepuasan kerja, dan balance scorecard terhadap kinerja karyawan. Hasil pengujian secara keseluruhan dengan uji $F$ (ANOVA) signifikansi $(0,000<0,05)$ artinya hipotesis diterima. Secara keseluruhan terdapat pengaruh kepemimpinan, komitmen organisasi, kepuasan kerja, dan balance scorecard terhadap kinerja karyawan.

\section{Koefisien Determinasi $\mathbf{R}^{2}$}

\begin{tabular}{|l|l|r|r|r|}
\hline \multicolumn{5}{|c|}{ Model Summary $^{\mathbf{b}}$} \\
Model & $\mathrm{R}$ & R Square & Adjusted R Square & \multicolumn{2}{c|}{$\begin{array}{c}\text { Std. Error of the } \\
\text { Estimate }\end{array}$} \\
\hline 1 & $.731^{\mathrm{a}}$ & .534 & .523 & \multicolumn{3}{|c|}{.30817 } \\
\hline
\end{tabular}

a. Predictors: (Constant), Balance Scorecard, Komitmen Organisasi,

Kepuasan Kerja, Kepemimpinan

b. Dependent Variable: Kinerja Karyawan

Tabel 3. Hasil Pengujian R-Square $\left(\mathrm{R}^{2}\right)$

Bahwa $\mathrm{R}^{2}$ sebesar $(0,534)$ atau $(53,4 \%)$. Angka tersebut menunjukkan bahwa sebesar 53,4 \% variasi variabel job performance dapat dijelaskan oleh variasi variabel kepemimpinan, komitmen organisasi, kepuasan kerja dan balance scorecard sisanya sebesar 46,6 \% dapat dijelaskan oleh variabel lainnya. 


\section{PENUTUP}

Simpulan. Salah satu kunci keberhasilan bagi sebagian besar perusahaan adalah sumber daya manusianya. Tidak hanya dari segi financial, tetapi dari segi sumber daya manusia yaitu performance dari karyawan. Hasil penelitian ini membuktikan bahwa dengan kepemimpinan, komitmen organisasi dan kepuasan kerja dari seorang karyawan sebuah perusahaan dapat mempengaruhi kinerja dari karyawan itu. Dan adanya balance scorecard yang diterapkan di perusahaan dapat menjadi acuan bagi karyawan untuk meningkatkan kinerjanya. Ketika kepemimpinan dari seorang atasan baik dan dapat memotivasi karyawan maka hal ini dapat meningkatkan kinerja dari karyawan. Komitmen organisasi pandangan bahwa karyawan akan berusaha untuk tetap komit terhadap organisasinya juga berpengaruh kepada kinerja soorang karyawan. Begitu juga jika karyawan merasa puas dengan pekerjaannya, atasan, lingkungan kerja, dan juga gaji maka hal ini dapat mempengaruhi kinerja dari karyawan tersebut. Demikian juga dengan balance scorecard, tools ini dapat dijadikan sebagai ukuran untuk kinerja karyawan dan dipenelitian itu juga ditemukan bahwa variable balance scorecard berpengaruh terhadap kinerja karyawan.

Saran. Hasil penelitian ini diharapkan dapat memberikan gambaran, referensi, dan juga masukan dalam pengambilan keputusan untuk peningkatan kinerja karyawan. Dapat digunakan sebagai bahan pertimbangan dalam pengambilan keputusan perusahaan agar dapat memperhatikan faktor kepemimpinan, komitmen organisasi, kepuasan kerja, dan balance scorecard dalam kegiatannya, dikarenakan dilihat dari hasil hipotesis dalam penelitian yang telah dilakukan bahwa faktor-faktor tersebut menjadi kontribusi yang berpengaruh dalam kinerja karyawan. Bagi peneliti lain, disarankan agar jangkauan pengambilan sampel diperbanyak dan untuk variable balance scorecard memakai empat perspektif, dikarenakan adanya keterbatasan penelitian ini hanya menggunakan dua persepektif yaitu pertumbuhan dan bisnis proses. Serta penelitian selanjutnya juga dapat menambah variable-variabel lainnya seperti job motivation, organizational culture, caring climate, dan organizational citizenship behavior.

\section{DAFTAR PUSTAKA}

Allen N J and Meyer J P (1990), "The Measurement and Antecedents of Affective, Continuance and Normative Commitment to the Organization", Journal of Occupational Psychology”.

FauzanBaihaqi (2010). "Pengaruh Gaya Kepemimpinan Terhadap Kepuasan Kerja dan Kinerja Dengan Komitmen Organisasi Sebagai Variabel Intervening"

Fu, W., \& Deshpande, S. P. (2013). "The Impact of Caring Climate, Job Satisfaction, and Organizational Commitment on Job Performance of Employees in a China's Insurance Company".

Hur et al. (2015). "The moderating role of perceived organizational support on the relationship between emotional labor and job-related outcomes".

Kaplan R.S. \& Norton D.P. (1992). The Balanced Scorecard- measures that drive Performance, Harvard Business Review.

Lee dan Zaman (2008). "The moderating effects of organizational culture on the relationships between leadership behaviour and organizational commitment and between organizational commitment and job satisfaction and performance".

Najjari et al. (2015). "An Investigation on the Effect of Balance Scorecard on Employees' Performances in Social Security Organization”. Journal of Natural and Social Sciences. Vol. 4. No. 1. 
Maleki, A. (2011). "Examining the relationship between organizational learning culture, and customer satisfaction in insurance industry".

Mumbi (2015). “The Balance Scorecard and The Employee Performance at Britam”.

Sawitri et al. (2016). " The Impact Of Job Satisfaction, Organization Commitment, Organization Citizenship Behavior (OCB) On Empolyess' Performance”.

Springer, G. J. (2011). “A Study of Job Motivation, Satisfaction, and Performance among Bank Employees".

Yassin et al. (2016). "Pengaruh Balance Scorecard dan Knowledge Management Terhadap Kinerja Karyawan dan Kinerja Perusahaan”. 


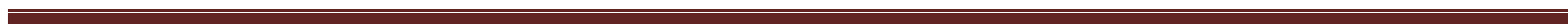
$\cdot$ 